\title{
Dental care utilization: examining the associations between health services deficits and not having a dental visit in past 12 months
}

\author{
M. Nawal Lutfiyya ${ }^{1,2^{*}}$ D, Andrew J. Gross ${ }^{2}$, Burke Soffe ${ }^{2}$ and Martin S. Lipsky²
}

\begin{abstract}
Background: A growing literature supports the contention that closing the divide between dental and medical care can improve access to and coordination of patient care. Health service deficits (HSDs) entail: no routine medical exam, no personal healthcare provider (HCP), no health insurance, and/or delaying medical care because of cost all within the last 12 months. Examining the associations between HSDs and dental care utilization could inform strategies and interventions aimed at narrowing the gap between the medical and dental professions. This study explored whether HSDs are associated with not having a dental care visit within the last 12 months. In addition, the study sought to provide an updated analysis of the characteristics and factors associated with dental care utilization.

Methods: Two thousand sixteen Behavioral Risk Factor Surveillance System survey data were analyzed using bivariate and multivariable techniques. The outcome variable for this study was: last dental visit was longer than 12 months ago.

Results: US adults without healthcare insurance, without a personal HCP, who had delayed medical care because of cost, and who had their last routine medical visit longer than 12 months ago had greater odds of not having a dental visit within the last 12 months. Further, this study identified disparities in dental care utilization among males, rural residents, those earning less than $\$ 50,000$ per year, Non-Hispanic Blacks and Non-Hispanic other races. Individuals with six or more and/or all of their permanent teeth removed and current smokers also had greater odds of not having had a dental care visit in the past 12 months.

Conclusions: Findings suggest that a stronger integration of medical and dental care might increase dental care utilization. In addition, persistent disparities in dental care utilization remain for several demographic groups. Targeted interventions offer the promise of helping achieve HP 2020 goals for improved oral health.
\end{abstract}

\section{Background}

In the United States (US) there has been a long standing separation between the dental and medical professions [1-4]. This divide persists despite: 1 ) recognition of the importance of oral health to the physical and social well-being of individuals and overall population health [5], and 2) burgeoning arguments that the integration of

\footnotetext{
* Correspondence: nlutfiyya@gmail.com

'Department of Pharmacy Practice and Pharmaceutical Sciences, College of Pharmacy, University of Minnesota, Minneapolis, MN, USA

${ }^{2}$ College of Dental Medicine, Roseman University of Health Sciences, 10920 S. River Front Parkway, South Jordan, Utah 84095, USA
}

dental and primary care might improve access to both [1-4]. There is a growing realization that comprehensive healthcare requires that the mouth needs to be put back into the body [1-4] and that oral health affects far more than teeth and a person's smile [6-14]. Bad dentition can lead to social stigmatization, poor self-esteem and negatively affect an individual's quality of life [9-11]. Good oral health is also acknowledged as a crucial contributory factor to an individual's overall health status [15]. Research demonstrates a connection between oral health and systemic illnesses including cardiovascular disease [6, 7], premature or low birth weight babies [16],

(c) The Author(s). 2019 Open Access This article is distributed under the terms of the Creative Commons Attribution 4.0 International License (http://creativecommons.org/licenses/by/4.0/), which permits unrestricted use, distribution, and 
depression [17, 18], asthma [19] and chronic obstructive pulmonary disease [20].

A growing literature [1-4] presents the case for reducing the divide between the practice of medicine and dentistry. Atchison and colleagues observed [3], that by integrating dental and medical care, access to and coordination of patient care is improved. A significant dimension of this integration entails interprofessional collaboration, an approach to healthcare delivery supported by the World Health Organization (WHO) [2]. Interprofessional collaboration occurs when healthcare personnel from different professions (such as medicine and dentistry) work together to provide comprehensive healthcare and related services to patients and communities [21].

Two leading Healthy People 2020 (HP2020) oral health indicators address the importance of receiving dental care as well as the importance of integrating dental and primary care [22]. These objectives are:

- Increase the proportions of children, adolescents, and adults who used the oral health care system in the past year with the target set at $49 \%$.

- Increase the proportion of local health departments and Federally Qualified Health Centers (FQHCs) that have an oral health program.

Increasing dental visits serves to identify and to treat existing dental disease as well as providing opportunities for preventive care and for identifying oral manifestations of systemic disease [23-26]. Supporting interprofessional care practice and collaboration by enhancing the US public health structure and FQHC network is one example that offers the potential of expanding dental care access.

Studies examining dental care utilization and HP2020 goals, also highlight the importance of understanding factors affecting dental care utilization [23-40]. Recent changes in the healthcare landscape influencing primary medical care may have also impacted dental care utilization. For example, the 2010 Affordable Care Act (ACA) [41] expanded Medicaid coverage for adults and one study attributed a 3 to $6 \%$ in dental care utilization to the ACA with the greatest impact on low income adults [31]. By mandating oral healthcare coverage for children up to age 21, the ACA might motivate adults without coverage to seek care for themselves if their children made regular dental visits.

Health service deficits (HSDs) [42-45] are an evolving concept that assess healthcare access and utilization. Conceptually healthcare access and utilization are distinct yet inter-related since access is necessary for utilization. According to the Institute of Medicine (IOM) access to health services entails "the timely use of personal health services to achieve the best health outcomes." [46] Access involves being able to make use of necessary healthcare (often through health insurance coverage), at a physical location (geographic availability), from a healthcare provider that the patient is able to communicate with and trusts (personal relationship) [47]. Healthcare utilization, in contrast, entails the actual use of healthcare services (e.g., mammograms, physical exams). Healthcare is accessed and used for a multiplicity of reasons such as preventing and treating health problems [48].

HSDs, as defined in this and other studies [42-45], include the factors of no routine medical exam in the past 12 months, not having a personal healthcare provider in the past 12 months, not having health insurance in the past 12 months, and having delayed medical care in the past 12 months because of cost. These four factors represent HSDs in part because of their direct (although not comprehensive) connection to preventive healthcare utilization and/or access to healthcare. At present, in the US, having health insurance and/or having the financial means for out-of-pocket costs often determines one's access to healthcare. The two factors of annual or routine medical check-ups (utilization) and/or having a personal healthcare provider (access) are essential for the receipt of preventive healthcare in the US.

The potential impact of HSDs is increasingly important in the social context of the changing landscape of healthcare. If US adults who haven't visited a dental professional in the past 12 months have additional HSDs, then integrating dental and primary care may be a key first step in expanding access to comprehensive care. Specifically, this study sought to investigate the question of whether HSDs are associated with US adults not having a dental care visit within the last 12 months. Examining the associations, if any, between HSDs and dental care utilization should inform health and dental care planners seeking to narrow the gap between the medical and dental professions with the goal of improving overall health. We hypothesize that after controlling for confounding covariates, HSDs are independently associated with not having had a dental visit in the past 12 months.

In addition to answering the research question posed, this study also provides an updated analysis of the characteristics and factors associated with dental utilization and identified risk factors associated with not visiting a dentist in the past 12 months. Exploring risk factors for underutilization provides insight into developing targeted strategies to address disparities in oral health [49]. This analysis is timely since a full assessment of HP2020's goal to achieve health equity is approaching. Implicit in HP2020's focus on health equity is an understanding of the foundational principles of social epidemiology that materially shape the way that diseases are experienced [50]. Societal factors continuously evolve 
and require periodic reinvestigation of risk factor patterns in order to develop interventions sensitive to changes in the relationship between health conditions and social factors [51].

\section{Methods}

This study analyzed 2016 Behavioral Risk Factor Surveillance System survey (BRFSS) data to answer the research question and to test the study hypothesis. Bivariate and multivariable techniques were used. Two thousand sixteen data were analyzed because these represent the most recently available BRFSS data set.

As a random digit telephone survey, BRFSS is a collaborative project between the CDC and all US states and territories. The survey is administered to the non-institutionalized US adult population aged 18 years and older. BRFSS uses a complex multi-stage sampling approach and develops a weighting factor for application to the data in order to ensure that they are representative of the non-institutionalized US population based on the most recent census data. A more in-depth description of the data weighting process can be found elsewhere [52].

BRFSS collects information from individuals on health risk behaviors, preventive health practices, chronic conditions, and healthcare access primarily related to chronic disease and injury. Further, the survey collects data on a number of demographic and health services variables. The survey is composed of core questions that must be asked of every survey participant, as well as optional modules that may be chosen by individual states and asked only of the survey respondents from those participating state(s). Two core questions addressing oral health are asked of all survey respondents. These are:

1) How long has it been since you last visited a dentist or a dental clinic for any reason? Include visits to dental specialists, such as orthodontists.

2) How many of your permanent teeth have been removed because of tooth decay or gum disease? Include teeth lost to infection, but do not include teeth lost for other reasons, such as injury or orthodontics. (If wisdom teeth are removed because of tooth decay or gum disease, they should be included in the count for lost teeth)

The dependent variable for this study was derived from responses to the first question on oral health and was: last dental visit was longer than 12 months ago. Responses to the second question comprised one of the independent variables--- number of permanent teeth removed. In addition, this study included 17 independent variables. The independent variables included in this study included six demographic variables (sex, age, marital status, geographic locale, race/ethnicity, and veteran status), three socio-economic variables (education attained, employment status, and annual household income), four health service variables (have a health care provider, delayed medical care because of cost, timing of last routine medical check-up, and health insurance status), three health variables (self-defined health status, number of permanent teeth removed, and smoking status), and one access to healthcare variable (dentists per 100,000 population in state of residence). All but one of the independent variables came from BRFSS. Active Dentists Per 100,000 Population [50], a state level variable, was merged with the 2016 BRFSS data.

For analysis, all variables (except sex) underwent re-coding. Re-coding for the most part entailed collapsing response categories and removing the response categories of don't know and refused. The categories of don't know and refused for all variables included in the study were treated as missing and removed from the analysis. All variable re-codes were undertaken for clarity of the factors used for analysis and ease of interpretation. Table 1 displays the study variables by their original factors and re-coded factors.

For instance, in BRFSS, marital status has nine categories. These were re-coded into three categories: Married, Not Married, and Partner in an Unmarried Couple because these three categories encapsulate the concepts of interest. Likewise, education had nine original categories that were reduced to three through re-coding. The re-coded categories (less than high school, high school graduate, and university graduate) represent the most meaningful ones for this analysis. The dependent variable, timing of last dental visit, had seven possible response categories; were reduced to two: last dental visit longer than 12 months ago/last dental visit within last 12 months. The first of these two categories or factors was used in a multivariable analysis as the dependent variable.

Income was re-coded as it was because the median household income in the US is estimated to be just over $\$ 50,000$. Our re-code as below $\$ 50,000$ and $\$ 50,000$ and higher was the closest approximation given the original categories provided in the BRFSS data analyzed.

Additionally, race/ethnicity was re-coded in the manner it was to avoid the issue of small cell numbers that are problematic for complex samples analyses. Also we re-coded age as we did because the first category 18-44 years takes into account that historically younger adults have been less likely to get annual check-ups regardless of health insurance status, they have also been less likely to have a PCP. While the implementation of the ACA is anticipated to impact access to and utilization of healthcare by younger adults, current research findings are mixed [53]. The ages 45 to 64 were grouped together because the range recognizes middle-aged adults who might be experiencing chronic conditions (e.g., hypertension) and hence 
Table 1 Study Variables Original and Re-coded Factors

\begin{tabular}{|c|c|c|c|}
\hline Variable Type & Study Variables & Original Factors & Re-coded Factors for Analysis \\
\hline \multirow[t]{8}{*}{ Dependent Variable } & \multirow[t]{8}{*}{ Last Dentist Visit ${ }^{a}$} & Within the past year & Within Last 12 Months ${ }^{\mathrm{b}}$ \\
\hline & & Within the past 2 years & \multirow[t]{4}{*}{ Longer Than 12 Months Ago } \\
\hline & & Within the past 5 years & \\
\hline & & 5 or more years ago & \\
\hline & & Never & \\
\hline & & Don't know/Not sure & \multirow[t]{3}{*}{ Removed for analysis } \\
\hline & & Refused & \\
\hline & & Missing & \\
\hline \multirow{29}{*}{$\begin{array}{l}\text { Demographic } \\
\text { Variables }\end{array}$} & \multirow[t]{2}{*}{ Sex } & Male & Male \\
\hline & & Female & Female \\
\hline & \multirow[t]{3}{*}{ Age } & \multirow[t]{3}{*}{ Age in years (18 to 99) } & 18-44 Years \\
\hline & & & 45-64 Years \\
\hline & & & 65 Years And Older \\
\hline & \multirow[t]{7}{*}{ Marital Status } & Married & Married \\
\hline & & Divorced & \multirow[t]{4}{*}{ Not Married } \\
\hline & & Widowed & \\
\hline & & Separated & \\
\hline & & Never married & \\
\hline & & A member of an unmarried couple & Partner In An Unmarried Couple \\
\hline & & Refused & Removed for analysis \\
\hline & \multirow[t]{4}{*}{ Geographic Locale } & In the center city of an MSA & \multirow[t]{3}{*}{ Metropolitan } \\
\hline & & $\begin{array}{l}\text { Outside the center city of an MSA but } \\
\text { inside the county containing the center city }\end{array}$ & \\
\hline & & Inside a suburban county of an MSA & \\
\hline & & Not in an MSA & Non-Metropolitan \\
\hline & \multirow[t]{9}{*}{ Race/Ethnicity } & White only, non-Hispanic & White Non-Hispanic \\
\hline & & Black only, non-Hispanic & Black Non-Hispanic \\
\hline & & $\begin{array}{l}\text { American Indian or Alaskan Native only, } \\
\text { Non-Hispanic }\end{array}$ & \multirow[t]{5}{*}{ Other Non-Hispanic } \\
\hline & & Asian only, non-Hispanic & \\
\hline & & $\begin{array}{l}\text { Native Hawaiian or other Pacific Islander } \\
\text { only, Non-Hispanic }\end{array}$ & \\
\hline & & Other race only, non-Hispanic & \\
\hline & & Multiracial, non-Hispanic & \\
\hline & & Hispanic & Hispanic \\
\hline & & Don't know/Not sure/Refused & Removed for analysis \\
\hline & \multirow[t]{4}{*}{ Veteran Status } & Yes & Veteran \\
\hline & & No & \multirow[t]{2}{*}{ Not A Veteran } \\
\hline & & Don't know/Not Sure & \\
\hline & & Refused & Removed for analysis \\
\hline \multirow{4}{*}{$\begin{array}{l}\text { Socio-economic } \\
\text { Variables }\end{array}$} & \multirow[t]{4}{*}{ Education Attained } & Never attended school or only kindergarten & \multirow[t]{3}{*}{ Less Than High School } \\
\hline & & Grades 1 through 8 (Elementary) & \\
\hline & & Grades 9 through 11 (Some high school) & \\
\hline & & Grade 12 or GED (High school graduate) & High School Graduate \\
\hline
\end{tabular}


Table 1 Study Variables Original and Re-coded Factors (Continued)

\begin{tabular}{|c|c|c|c|}
\hline Variable Type & Study Variables & Original Factors & Re-coded Factors for Analysis \\
\hline & & school) & \\
\hline & & College 4 years or more (College graduate) & University Graduate \\
\hline & & Refused & Removed for analysis \\
\hline & Employment Status & Employed for wages & Employed \\
\hline & & Self-employed & \\
\hline & & Out of work for 1 year or more & Not Employed \\
\hline & & Out of work for less than 1 year & \\
\hline & & A homemaker & Not Working By Choice Or Unable \\
\hline & & A student & . \\
\hline & & Retired & \\
\hline & & Unable to work & \\
\hline & & Refused & Removed for analysis \\
\hline & Annual Household Income & Less than $\$ 10,000$ & Less Than $\$ 50,000$ \\
\hline & & $\$ 10,000$ to less than $\$ 15,000$ & \\
\hline & & $\$ 15,000$ to less than $\$ 20,000$ & \\
\hline & & $\$ 20,000$ to less than $\$ 25,000$ & \\
\hline & & $\$ 25,000$ to less than $\$ 35,000$ & \\
\hline & & $\$ 35,000$ to less than $\$ 50,000$ & \\
\hline & & $\$ 50,000$ to less than $\$ 75,000$ & $\$ 50,000$ And More \\
\hline & & $\$ 75,000$ or more & \\
\hline & & Don't know/Not sure & Removed for analysis \\
\hline & & Refused & \\
\hline \multirow{21}{*}{$\begin{array}{l}\text { Health Services } \\
\text { Variables }\end{array}$} & Health Insurance Status & Yes & Have Health Insurance \\
\hline & & No & Do Not Have Health Insurance \\
\hline & & Don't know/Not Sure & \\
\hline & & Refused & Removed for analysis \\
\hline & Personal HCP & Yes, only one & Have HCP \\
\hline & & More than one & \\
\hline & & No & Do Not Have HCP \\
\hline & & Don't know/Not Sure & \\
\hline & & Refused & Removed for analysis \\
\hline & & Not asked or Missing & \\
\hline & Delayed Care Because Of Cost & Yes & Care Delayed \\
\hline & & No & Care Not Delayed \\
\hline & & Don't know/Not sure & Removed for analysis \\
\hline & & Refused & \\
\hline & Last Medical Checkup & Within past year & Within Last 12 Months \\
\hline & & Within past 2 years & Longer Than 12 Months Ago \\
\hline & & Within past 5 years & \\
\hline & & 5 or more years ago & \\
\hline & & Don't know/Not sure & \\
\hline & & Never & \\
\hline & & Refused & Removed for analysis \\
\hline Health Specific & Number Permanent Teeth & None & No Teeth \\
\hline
\end{tabular}


Table 1 Study Variables Original and Re-coded Factors (Continued)

\begin{tabular}{|c|c|c|c|}
\hline Variable Type & Study Variables & Original Factors & Re-coded Factors for Analysis \\
\hline \multirow[t]{14}{*}{ Variables } & \multirow[t]{4}{*}{ Removed } & 1 to 5 & 1 To 5 Teeth \\
\hline & & 6 or more, but not all & 6 Or More, But Not All Teeth \\
\hline & & All & All Teeth \\
\hline & & $\begin{array}{l}\text { Don't know/Not sure } \\
\text { Refused }\end{array}$ & Removed for analysis \\
\hline & \multirow[t]{7}{*}{ Self-Defined Health Status } & Excellent & \multirow[t]{3}{*}{ Good To Excellent Health } \\
\hline & & Very good & \\
\hline & & Good & \\
\hline & & Fair & \multirow[t]{2}{*}{ Fair To Poor Health } \\
\hline & & Poor & \\
\hline & & Don't know/Not Sure & \multirow[t]{2}{*}{ Removed for analysis } \\
\hline & & Refused & \\
\hline & \multirow[t]{3}{*}{ Smoking Status } & No & Non-Smoker \\
\hline & & Yes & Current Smoker \\
\hline & & Don't know/Refused/Missing & Removed for analysis \\
\hline \multirow{3}{*}{$\begin{array}{l}\text { Access To Dental } \\
\text { Care Variable }\end{array}$} & \multirow{3}{*}{$\begin{array}{l}\text { Dentists Per 100,000 Population } \\
\text { Tertile Ranges }\end{array}$} & \multirow{3}{*}{$\begin{array}{l}\text { Dentists per } 100,000 \text { state population } \\
\text { ranging from } 40.93 \text { to } 89.95\end{array}$} & 40.93-57.23 Per 100,000 \\
\hline & & & 57.24-73.54 Per 100,000 \\
\hline & & & 73.55-89.85 Per 100,000 \\
\hline
\end{tabular}

a Dependent Variable for Bivariate and Logistic Regression Analysis

${ }^{\mathrm{b}}$ Reference Category for Logistic Regression Analysis

health insurance, annual check-ups, having a PCP would all be acutely important. Finally, the range 65 and older was chosen because of Medicare eligibility for that age group.

While rurality has been defined in multiple and not always compatible ways, [54] in this study the geographic locale variable was determined using the metropolitan statistical area (MSA) variable provided in the BRFSS database. MSA is comprised of geographic entities delineated by the Office of Management and Budget (OMB) for use by Federal statistical agencies in collecting, tabulating, and publishing federal statistics [54]. The MSA variable was recoded into the dichotomous categories of rural and metropolitan. Rural residents were defined as people living either within an MSA that had no center city or outside an MSA. Metropolitan residents included all US adults living in a center city of an MSA, outside the center city of an MSA but inside the county containing the center city, or inside a suburban county of an MSA.

The variable active dentists per 100,000 state population was merged with the 2016 BRFSS database. This variable was then recoded into tertiles for analysis. The original data for this variable is collected annually by the American Dental Association [55] and represents an estimate of all active dentists by state. The re-coding was undertaken to organize the data into categories corresponding to high, medium and low access to dental professionals.
All analyses were performed on weighted data as recommended by the CDC. The weighting, calculated by the $\mathrm{CDC}$, uses the most recently available census data to provide a stratified representation of the nation's non-institutionalized population. All of the performed analyses used the complex samples module available in SPSS. For bivariate analysis, an adjusted F statistic was calculated as the test statistic. For the multivariable analysis performed, an adjusted odds ratio was the calculated test statistic. Only findings from weighted analyses were considered valid. All analyses were performed using SPSS version 25 (IBM, Chicago, IL, USA) with alpha set at $<0.05$. The Institutional Review Boards (IRBs) of the researchers' institutions recognize that the analysis of de-identified, publicly available data does not constitute human subjects research as defined in federal regulations, and as such does not require IRB review. Hence, human subjects review was not sought.

\section{Results}

Table 2 summarizes the study variables and study population weighted frequencies and percentages. For the dependent variable---timing of last dental visit---30.4\% of the study population had not had a dental visit in the past 12 months. Also in Table 2, 48.4\% of the study population lived in states with the fewest dentists per 100,000 population. Further, while $46.7 \%$ of the study population reported having no permanent teeth removed, $7.4 \%$ reported having had all of their permanent 
Table 2 Description of Non-Institutionalized US Adults Included in Oral Health Study 2016 BRFSS Data (weighted n=60,512,412)

\begin{tabular}{|c|c|c|c|c|}
\hline \multirow{2}{*}{$\begin{array}{l}\text { Variable Category } \\
\text { Dependent Variable }\end{array}$} & \multicolumn{2}{|l|}{ Study Variables and Factors } & \multirow{2}{*}{$\begin{array}{l}\text { Frequency } \\
18,395,902\end{array}$} & \multirow{2}{*}{$\frac{\text { Percent }}{30.4 \%}$} \\
\hline & Last Dentist Visit ${ }^{a}$ & Longer Than 12 Months Ago & & \\
\hline & & Within Last 12 Months ${ }^{\mathrm{b}}$ & $42,116,510$ & $69.6 \%$ \\
\hline \multirow[t]{16}{*}{ Demographic Variables } & Sex & Male & $25,905,063$ & $42.8 \%$ \\
\hline & & Female & $34,607,349$ & $57.2 \%$ \\
\hline & Age Ranges & 18-44 Years & $14,512,974$ & $24.0 \%$ \\
\hline & & 45-64 Years & $24,921,543$ & $41.2 \%$ \\
\hline & & 65 Years And Older & $21,077,895$ & $34.8 \%$ \\
\hline & Marital Status & Married & $37,034,620$ & $61.2 \%$ \\
\hline & & Not Married & $21,789,874$ & $36.0 \%$ \\
\hline & & Partner In An Unmarried Couple & $1,687,918$ & $2.8 \%$ \\
\hline & Geographic Locale & Metropolitan & $49,128,575$ & $81.2 \%$ \\
\hline & & Rural & $11,383,837$ & $18.8 \%$ \\
\hline & Race/Ethnicity & White Non-Hispanic & $45,324,018$ & $74.9 \%$ \\
\hline & & Black Non-Hispanic & $6,427,112$ & $10.6 \%$ \\
\hline & & Other Non-Hispanic & $3,519,669$ & $5.8 \%$ \\
\hline & & Hispanic & $5,241,613$ & $8.7 \%$ \\
\hline & Veteran Status & Veteran & $7,987,900$ & $13.2 \%$ \\
\hline & & Not A Veteran & $52,524,511$ & $86.8 \%$ \\
\hline \multirow[t]{8}{*}{ Socio-economic Variables } & Education Attained & Less Than High School & $6,685,394$ & $11.0 \%$ \\
\hline & & High School Graduate & $36,053,302$ & $59.6 \%$ \\
\hline & & University Graduate & $17,773,715$ & $29.4 \%$ \\
\hline & Employment Status & Employed & $28,767,825$ & $47.5 \%$ \\
\hline & & Not Employed & $2,395,899$ & $4.0 \%$ \\
\hline & & $\begin{array}{l}\text { Not Working By Choice Or Unable } \\
\text { To Work }\end{array}$ & $29,348,688$ & $48.5 \%$ \\
\hline & Annual Household Income & Less Than $\$ 50,000$ & $29,657,890$ & $49.0 \%$ \\
\hline & & $\$ 50,000$ And More & $30,854,522$ & $51.0 \%$ \\
\hline \multirow[t]{8}{*}{ Health Services Variables } & Health Insurance Status & Have Health Insurance & $56,855,272$ & $94.0 \%$ \\
\hline & & Do Not Have Health Insurance & $3,657,140$ & $6.0 \%$ \\
\hline & Personal HCP & Have HCP & $53,623,164$ & $88.6 \%$ \\
\hline & & Do Not Have HCP & $6,889,248$ & $11.4 \%$ \\
\hline & Delayed Care Because Of Cost & Care Delayed & $5,576,447$ & $9.2 \%$ \\
\hline & & Care Not Delayed & $54,935,965$ & $90.8 \%$ \\
\hline & Last Medical Checkup & Within Last 12 Months & $471,843,067$ & $78.0 \%$ \\
\hline & & Longer Than 12 Months Ago & $13,328,105$ & $22.0 \%$ \\
\hline \multirow[t]{8}{*}{ Health Specific Variables } & Number Permanent Teeth & No Teeth & $28,245,450$ & $46.7 \%$ \\
\hline & Removed & 1 To 5 Teeth & $19,294,234$ & $31.9 \%$ \\
\hline & & 6 Or More, But Not All Teeth & $8,480,363$ & $14.0 \%$ \\
\hline & & All Teeth & $4,492,364$ & $7.4 \%$ \\
\hline & Self-Defined Health Status & Good To Excellent Health & $48,713,690$ & $80.5 \%$ \\
\hline & & Fair To Poor Health & $11,798,722$ & $19.5 \%$ \\
\hline & Smoking Status & Non-Smoker & $51,886,829$ & $85.7 \%$ \\
\hline & & Current Smoker & $8,625,583$ & $14.3 \%$ \\
\hline
\end{tabular}


Table 2 Description of Non-Institutionalized US Adults Included in Oral Health Study 2016 BRFSS Data (weighted $n=60,512,412$ ) (Continued)

\begin{tabular}{|c|c|c|c|c|}
\hline Variable Category & Study Variables and Factors & & Frequency & Percent \\
\hline \multirow[t]{3}{*}{ Access To Dental Care Variable } & \multirow{3}{*}{$\begin{array}{l}\text { Dentists Per 100,000 Population } \\
\text { Tertile Ranges }^{c}\end{array}$} & 40.93-57.23 Per 100,000 & $29,301,599$ & $48.4 \%$ \\
\hline & & 57.24-73.54 Per 100,000 & $16,466,143$ & $27.2 \%$ \\
\hline & & 73.55-89.85 Per 100,000 & $14,744,670$ & $24.4 \%$ \\
\hline
\end{tabular}

${ }^{\mathrm{a}}$ Dependent Variable for Bivariate and Logistic Regression Analysis

${ }^{\mathrm{b}}$ Reference Category for Logistic Regression Analysis

${ }^{\mathrm{C}} \mathrm{To}$ convert a rate per 100,000 to a percentage move the decimal point three digits to the left

teeth removed. Additionally, $14.3 \%$ reported that they were currently smokers.

Table 3 displays the results of the bivariate analysis. This analysis yielded that each independent variable and related factors were significantly associated $(p<0.05)$ with the study's dependent variable. The bivariate analysis was performed to determine which independent variables should be included in the complex samples logistic regression analysis. Since all of the independent variables had a statistically significant relationship with the dependent variable, a decision was made to include all of the independent variables in the multivariable logistic regression model tested.

Table 4 displays the results of the complex samples logistic regression analysis performed using last dental visit longer than 12 months ago as the dependent variable. Seventeen independent variables constituting 26 factors were included in the analysis. Of the demographic variables included in the logistic regression analysis, three (sex, geographic locale, race/ethnicity) yielded significant results for one or more factors. Males, when compared to females, had greater odds of not having had a dental visit in the past 12 months (OR 1.370, CI 1.240-1.455) as did adults living in a rural area (OR 1.095, CI 1.034-1.160) when compared to those living in a metropolitan one. Analysis of the race/ethnicity factors indicated that Non-Hispanic Blacks (OR 1.296, CI 1.187-1.416) and Non-Hispanic Other races (OR 1.155, CI 1.011-1.320) had significantly greater odds of not having visited a dentist in the last 12 months when compared to Non-Hispanic Whites.

All of the socioeconomic variables (education attained, employment status, annual household income) included in the logistic regression analysis yielded significant results for one or more factors with adults with less than a high school education (OR 2.28, CI 2.004-2.477) as well as those with only a high school education (OR 1.555, CI 1.467-1.648) having greater odds of not having seen a dentist in the past 12 months when compared to adults who were university graduates. Additionally, US adults who reported being unemployed (OR 1.174, CI 1.0271.343), in contrast to employed, and/or having an annual household income of less than $\$ 50,000$ (OR 1.992, CI 1.871-2.120), rather than $\$ 50,000$ and higher, had greater odds of not having had a dental visit in the last 12 months.

All four health services deficits variables (last routine medical exam, have personal healthcare provider, health insurance status, and/or delayed medical care because of cost) included in the logistic regression analysis showed significant results. US adults without health insurance (OR 1.317, CI 1.162-1.491) rather than with health insurance, without a personal HCP (OR 1.396, CI 1.2791.525) rather than with a HCP, who had delayed medical care because of cost (OR 1.568, CI 1.428-1.721) rather than not deferring cast because of cost, and who had their last routine medical visit longer than 12 months ago (OR 1.877, CI 1.756-2.005) rather than within the last 12 months had greater odds of not having a dental visit within the last 12 months.

Of the three health variables included in the complex samples logistic regression analysis (self-defined health status, number of permanent teeth removed, and smoking status), all yielded significant results. US adults who defined their health status as fair to poor (OR 1.523, CI 1.427-1.626) rather than good to excellent, had six or more (OR 1.380, CI 1.286-1.502) and/or all of their permanent teeth (OR 6.331, CI 5.721-7.00) removed rather than none of their teeth removed, and were current smokers (OR 1.472, CI 1.373-1.578) rather than non-smokers had greater odds of not having had a dental visit in the past 12 months. Finally, US adults living in states with the fewest number of active dentists per 100,000 population (OR 1.185, CI 1.103-1.274) rather than the highest number of active dentists per 100,000 population had greater odds of not having had a dental visit in the past 12 months.

\section{Discussion}

Evidence supports the connection between oral health and overall health [6-14] and an understanding of the risk factors associated with oral health disparities provides insight about the health service needs within a population. To gain a better understanding of these risk factors, this study explored the associations between HSDs and not visiting a dental professional in the past 12 months. Enhancing the utilization of dental services 
Table 3 Complex Samples: Bivariate Analysis Last Dental Visit by Study Covariates 2016 BRFSS Data

\begin{tabular}{|c|c|c|c|c|c|}
\hline \multirow[t]{2}{*}{ Variable Category } & \multirow[t]{2}{*}{ Covariates and Factors } & & \multicolumn{2}{|l|}{ Last Dentist Visit } & \multirow[t]{2}{*}{$p$-value* } \\
\hline & & & $\begin{array}{l}\text { Longer Than } 12 \text { Months } \\
\text { Ago }\end{array}$ & $\begin{array}{l}\text { Within Last } \\
12 \text { Months }\end{array}$ & \\
\hline \multirow[t]{16}{*}{ Demographic Variables } & \multirow[t]{2}{*}{ Sex } & Male & $46,602,666$ / 52.7\% & $76,940,221 / 46.5 \%$ & \multirow[t]{2}{*}{.000} \\
\hline & & Female & $41,854,895 / 47.3 \%$ & $88,495,464$ / 53.5\% & \\
\hline & \multirow[t]{3}{*}{ Age Ranges } & 18-44 Years & $42,687,478 / 48.2 \%$ & $75,122,926 / 45.4 \%$ & \multirow[t]{3}{*}{.000} \\
\hline & & 45-64 Years & $28,494,110 / 32.2 \%$ & $56,817,450$ / 34.3\% & \\
\hline & & 65 Years And Older & $17,291,479$ / 19.5\% & $33,508,777$ / 20.3\% & \\
\hline & \multirow[t]{3}{*}{ Marital Status } & Married & $37,154,844$ / 42.3\% & $90,321,846 / 55.0 \%$ & \multirow[t]{3}{*}{.000} \\
\hline & & Not Married & $45,303,410 / 51.5 \%$ & $67,051,356 / 40.8 \%$ & \\
\hline & & $\begin{array}{l}\text { Partner In An Unmarried } \\
\text { Coupled }\end{array}$ & $5,450,378 / 6.2 \%$ & $6,851,984$ / 4.2\% & \\
\hline & \multirow[t]{2}{*}{ Geographic Locale } & Metropolitan & $18,962,965 / 77.1 \%$ & $45,517,333 / 83.4 \%$ & \multirow[t]{2}{*}{.000} \\
\hline & & Rural & $5,625,139 / 22.9 \%$ & $9,036,397 / 16.6 \%$ & \\
\hline & \multirow[t]{4}{*}{ Race and Ethnicity } & White Non-Hispanic & $49,433,721 / 57.0 \%$ & $107,745,288$ / 66.3\% & \multirow[t]{4}{*}{.000} \\
\hline & & Black Non-Hispanic & $12,121,155 / 14.0 \%$ & $17,291,109$ / 10.6\% & \\
\hline & & Other Non-Hispanic & $6,872,299 / 7.9 \%$ & $13,582,687 / 8.4 \%$ & \\
\hline & & Hispanic & $18,224,520$ / 21.0\% & $23,895,023 / 14.7 \%$ & \\
\hline & \multirow[t]{2}{*}{ Veteran Status } & Veteran & $8,762,047$ / 9.9\% & $18,220,075$ / 11.0\% & \multirow[t]{2}{*}{.000} \\
\hline & & Not A Veteran & $79,426,563 / 90.1 \%$ & $146,770,809$ / 89.0\% & \\
\hline \multirow{8}{*}{$\begin{array}{l}\text { Socio-economic } \\
\text { Variables }\end{array}$} & \multirow[t]{3}{*}{ Education Attained } & Less Than HS & $19,851,625 / 22.6 \%$ & $15,425,520 / 9.4 \%$ & \multirow[t]{3}{*}{.000} \\
\hline & & HS Graduate & $54,196,392$ / 61.6\% & $95,552,211 / 58.0 \%$ & \\
\hline & & University Graduate & $13,978,080 / 15.9 \%$ & $53,802,139 / 32.7 \%$ & \\
\hline & \multirow[t]{3}{*}{ Employment Status } & Employed & $46,559,563 / 52.6 \%$ & $96,839,752$ / 58.5\% & \multirow[t]{3}{*}{.000} \\
\hline & & Not Employed & $6,439,077 / 7.3 \%$ & $7,109,706 / 4.3 \%$ & \\
\hline & & $\begin{array}{l}\text { Not Working By Choice Or } \\
\text { Unable To Work }\end{array}$ & $35,449,462 / 40.1 \%$ & $61,454,059 / 37.2 \%$ & \\
\hline & \multirow[t]{2}{*}{ Annual Household Income } & Less Than $\$ 50,000$ & $50,843,550 / 69.7 \%$ & $59,608,418 / 43.1 \%$ & \multirow[t]{2}{*}{.000} \\
\hline & & $\$ 50,000$ And More & $22,098,057 / 30.3 \%$ & $78,628,095$ / 56.9\% & \\
\hline \multirow{8}{*}{$\begin{array}{l}\text { Health Services } \\
\text { Variables }\end{array}$} & Health Insurance Status & Have Health Insurance & $70,404,914 / 80.1 \%$ & $152,925,843 / 92.9 \%$ & .000 \\
\hline & & $\begin{array}{l}\text { Do Not Have Health } \\
\text { Insurance }\end{array}$ & $17,458,226 / 19.9 \%$ & $11,647,884 / 7.1 \%$ & \\
\hline & Personal HCP & Have HCP & $59,975,447 / 67.9 \%$ & $137,436,415$ / 83.2\% & .000 \\
\hline & & Do Not Have HCP & $28,336,795 / 32.1 \%$ & $27,810,053 / 16.8 \%$ & \\
\hline & Delayed Care Because & Care Delayed & $18,110,419$ / 20.6\% & $14,939,460 / 9.0 \%$ & .000 \\
\hline & & Care Not Delayed & $70,017,530 / 79.4 \%$ & $150,164,890 / 91.0 \%$ & \\
\hline & Last Medical Checkup & Within Last 12 Months & $52,110,157 / 59.0 \%$ & $126,703,017 / 76.7 \%$ & .000 \\
\hline & & Longer Than 12 Months Ago & $36,246,201 / 41.0 \%$ & $38,568,615$ / 23.3\% & \\
\hline Health Specific & Number Permanent Teeth & No Teeth & $42,866,454 / 49.5 \%$ & $96,478,778 / 59.2 \%$ & .000 \\
\hline & & 1 To 5 Teeth & $23,915,004 / 27.6 \%$ & $48,736,369$ / 29.9\% & \\
\hline & & 6 Or More, But Not All Teeth & $10,663,744$ / 12.3\% & $14,325,222$ / $8.8 \%$ & \\
\hline & & All Teeth & $9,108,344 / 10.5 \%$ & $3,301,783 / 2.0 \%$ & \\
\hline & Self-Defined Health Status & Good To Excellent Health & $64,961,197 / 73.7 \%$ & $142,814,027$ / 86.5\% & .000 \\
\hline & & Fair To Poor Health & $23,137,576 / 26.3 \%$ & $22,321,669$ / 13.5\% & \\
\hline & Smoking Status & Non-Smoker & $63,410,623 / 75.8 \%$ & $138,254,361$ / 87.9\% & .000 \\
\hline & & Current Smoker & $20,248,194$ / 24.2\% & $19,040,890 / 12.1 \%$ & \\
\hline
\end{tabular}


Table 3 Complex Samples: Bivariate Analysis Last Dental Visit by Study Covariates 2016 BRFSS Data (Continued)

\begin{tabular}{|c|c|c|c|c|c|}
\hline \multirow[t]{2}{*}{ Variable Category } & \multirow[t]{2}{*}{ Covariates and Factors } & & \multicolumn{2}{|l|}{ Last Dentist Visit } & \multirow[t]{2}{*}{$p$-value* } \\
\hline & & & $\begin{array}{l}\text { Longer Than } 12 \text { Months } \\
\text { Ago }\end{array}$ & $\begin{array}{l}\text { Within Last } \\
12 \text { Months }\end{array}$ & \\
\hline \multirow{3}{*}{$\begin{array}{l}\text { Access To Dental } \\
\text { Care Variable }\end{array}$} & \multirow{3}{*}{$\begin{array}{l}\text { Dentists Per } 100,000 \\
\text { Population Tertile Ranges }\end{array}$} & 40.93-57.23 Per 100,000 & $47,857,926 / 54.7 \%$ & $77,433,898$ / 47.4\% & \multirow[t]{3}{*}{.000} \\
\hline & & 57.24-73.54 Per 100,000 & $19,880,342$ / 22.7\% & $42,160,943$ / 25.8\% & \\
\hline & & 73.55-89.85 Per 100,000 & $19,771,381 / 22.6 \%$ & $43,828,997$ / 26.8\% & \\
\hline
\end{tabular}

*Significance is based on the adjusted $\mathrm{F}$ and its degrees of freedom

is a fundamental step for addressing oral health disparities in the US.

A key finding of this analysis is that one-third of US adults had not seen a dentist within the past 12 months, which despite HP2020's emphasis on oral health is a level similar to previously reported levels (approximately 32\%) [56]. In contrast, $22.0 \%$ of US adults had not had a routine medical checkup within the past 12 months (a 36.4\%difference from the proportion of US adults seeing a dental professional in the past 12 months). Since more adults visit a physician annually than a dental professional, this suggests that a more robust integration of dental with medical services might increase access to and utilization of dental care. Such an integration could increase bi-directional referrals and better coordination of necessary care (both primary care and dental care) [1-4]. For example, a dentist may be asked by a patient to address an esthetic issue yet have signs and symptoms of an uncontrolled chronic illness that merits referral to a medical practitioner. While both the American Dental Association and American Medical Association have referral guidelines within their disciplines, neither publishes guidelines for integrating dental and medical care [57].

Our findings revealed that all four of the HSD variables examined---no health insurance, no personal HCP, delaying healthcare because of cost, and last routine medical visit longer than 12 months ago---were significantly associated with not visiting a dental professional in the last 12 months. These findings suggest that strategies to integrate dental care and medical care which address HSDs have the potential to improve overall health. If nothing else, inclusive medical insurance coverage must embrace oral health. These insurance plans should be affordable (to avoid delaying care because of cost) and mandate care coordination in order to truly support comprehensive healthcare. At present an estimated 67\% of working age US adults have some form of dental insurance while $83 \%$ of same age adults have health insurance. Furthermore, the burden of unaddressed dental disease falls, for the most part, on the medical and not dental care system [58].

In addition to HSDs, this study updated risk factors and identified several other. potential areas of focus to improve dental care utilization. Populations with a higher socioeconomic burden, racial minorities, males, and those with less education all had greater odds of not having seen a dentist in the past 12 months. Hence, similar to all healthcare, improving/increasing access to dental care requires at the minimum taking socioeconomic factors into account. Presently, dental insurance limitations remain a persistent deterrent to preventive and restorative dental care [59]. The ACA attempts to tackle these socioeconomic barriers. However, despite Medicaid expansion, the ACA impact on oral health has been small [60-63]. As currently constructed, the ACA only modestly increased dental care utilization for children [32] and does not appear to have had a substantial impact on dental care among adults [64]. This is not surprising since there is no adult dental insurance requirement in the ACA and Medicaid payments for dental care are often low. While strengthening and utilizing the ACA as a tool to coordinate dental and medical services with enhanced dental coverage represents one strategy to improve the quality and efficiency of overall healthcare (health and dental), the current political climate could lead to any number of possibilities from repeal to reform. Since the current state of public opinion favors maintaining and reforming the ACA [65], this moment in history might present an opportunity to address the importance of oral health in a meaningful way.

Rural residency emerged as an independent factor associated with lower dental care utilization even after controlling for HSDs, socioeconomic factors, demographics, and dentist supply. While an earlier study looking at a single state [66] did not associate rurality with dental care utilization, our results suggest that factors unique to a rural setting might play a role in dental care utilization and that rural residents may benefit from programs targeted at rural settings. Other researchers found that rural residents are more likely than their non-rural counterparts to delay dental care until being in pain, [67] suggesting a potential benefit from educational programs targeted at the importance of preventive care and early intervention. Addressing rural needs is especially important since rural adults are more likely to have untreated dental disease and poorer oral health. In rural 
Table 4 Complex Samples Logistic Regression Analysis: Last Dental Visit Longer than 12 Months Ago as Dependent Variable 2016 BRFSS Data

\begin{tabular}{|c|c|c|c|c|c|}
\hline \multirow[t]{2}{*}{ Variable Category } & \multirow[t]{2}{*}{ Covariates } & \multirow[t]{2}{*}{ Factors } & \multirow{2}{*}{$\begin{array}{l}\text { Adjusted } \\
\text { Odds } \\
\text { Ratio }\end{array}$} & \multicolumn{2}{|c|}{ 95\% Confidence Interva } \\
\hline & & & & Lower & Upper \\
\hline \multirow[t]{10}{*}{ Demographic Variables } & Sex & Male vs. Female & 1.370 & 1.290 & 1.455 \\
\hline & \multirow[t]{2}{*}{ Age Ranges } & 18-44 Years vs. 65 Years And Older & 1.090 & .997 & 1.191 \\
\hline & & 45-64 Years vs. 65 Years And Older & 1.050 & .982 & 1.123 \\
\hline & \multirow[t]{2}{*}{ Marital Status } & $\begin{array}{l}\text { Married vs. Partner In An Unmarried } \\
\text { Coupled }\end{array}$ & .878 & .724 & 1.066 \\
\hline & & $\begin{array}{l}\text { Not Married vs. Partner In An Unmarried } \\
\text { Coupled }\end{array}$ & .964 & .793 & 1.170 \\
\hline & Geographic Locale & Rural vs. Metropolitan & 1.095 & 1.034 & 1.160 \\
\hline & \multirow[t]{3}{*}{ Race And Ethnicity } & Black Non-Hispanic vs. White Non-Hispanic & 1.296 & 1.187 & 1.416 \\
\hline & & Other Non-Hispanic vs. White Non-Hispanic & 1.155 & 1.011 & 1.320 \\
\hline & & Hispanic vs. White Non-Hispanic & 1.051 & .929 & 1.188 \\
\hline & Veteran Status & Veteran vs. Not A Veteran & .945 & .873 & 1.024 \\
\hline \multirow[t]{5}{*}{ Socio-economic Variables } & \multirow[t]{2}{*}{ Education Attained } & Less Than High School vs. University Graduate & 2.228 & 2.004 & 2.477 \\
\hline & & HS Graduate vs. University Graduate & 1.555 & 1.467 & 1.648 \\
\hline & \multirow[t]{2}{*}{ Employment Status } & Not Employed vs. Employed & 1.174 & 1.027 & 1.343 \\
\hline & & $\begin{array}{l}\text { Not Working By Choice Or Unable To Work vs. } \\
\text { Employed }\end{array}$ & 1.021 & .955 & 1.092 \\
\hline & Annual Household Income & Less Than $\$ 50,000$ vs. $\$ 50,000$ And More & 1.992 & 1.871 & 2.120 \\
\hline \multirow[t]{4}{*}{ Health Services Variables } & Health Insurance Status & $\begin{array}{l}\text { Do Not Have Health Insurance vs. Have Health } \\
\text { Insurance }\end{array}$ & 1.317 & 1.162 & 1.491 \\
\hline & Personal HCP & Do Not Have HCP vs. Have HCP & 1.396 & 1.279 & 1.525 \\
\hline & Delayed Care Because Of Cost & Care Delayed vs. Care Not Delayed & 1.568 & 1.428 & 1.721 \\
\hline & Last Medical Checkup & $\begin{array}{l}\text { Longer Than } 12 \text { Months Ago vs. Within Last } \\
12 \text { Months }\end{array}$ & 1.877 & 1.756 & 2.005 \\
\hline \multirow[t]{5}{*}{ Health Specific Variables } & Self-Defined Health Status & $\begin{array}{l}\text { Fair to Poor Health vs. Good to Excellent } \\
\text { Health }\end{array}$ & 1.523 & 1.427 & 1.626 \\
\hline & \multirow{3}{*}{$\begin{array}{l}\text { Number Permanent Teeth } \\
\text { Removed }\end{array}$} & 1 To 5 Teeth Vs. No Teeth & .991 & .932 & 1.055 \\
\hline & & 6 Or More, But Not All Teeth Vs. No Teeth & 1.390 & 1.286 & 1.502 \\
\hline & & All Teeth Vs. No Teeth & 6.331 & 5.721 & 7.007 \\
\hline & Smoking Status & Current Smoker vs. Non-Smoker & 1.472 & 1.373 & 1.578 \\
\hline \multirow[t]{2}{*}{$\begin{array}{l}\text { Access To Dental Care } \\
\text { Variable }\end{array}$} & \multirow[t]{2}{*}{$\begin{array}{l}\text { Dentists Per } 100,000 \\
\text { Population Tertile Ranges }\end{array}$} & $\begin{array}{l}\text { 40.93-57.23 Per } 100,000 \text { vs. } 73.55-89.85 \\
\text { Per } 100,000\end{array}$ & 1.185 & 1.103 & 1.274 \\
\hline & & $\begin{array}{l}57.24-73.54 \text { Per } 100,000 \text { vs. } 73.55-89.85 \\
\text { Per } 100,000\end{array}$ & .999 & .924 & 1.080 \\
\hline
\end{tabular}

American there are more physicians per capita then dentists [68] and Khan, et al. [69] recommended enhancing the integration of rural oral healthcare into primary care as a strategy to mitigate the challenges of providing dental care in rural settings.

The study results also revealed that those with no teeth or fewer teeth were far less likely to seek dental care. Tooth loss or being edentulous increases the risk of oral cancer by 2 to 3 fold even after controlling for smoking and alcohol use [70]. Failure to have regular dental care might be a missed opportunity for detecting cancer in an earlier stage which improves outcomes [71].
In addition, routine dental care helps preserve existing teeth which is associated with better health outcomes. Our finding suggests that establishing a recommendation for dental assessment as part of routine medical care for those with teeth loss offers the potential for improving the health of these individuals.

This study does have several limitations. One limitation to consider in interpreting the data is the absence of information on the purpose of the dental visit. Regularly scheduled maintenance provides oral disease prevention and early detection. Dental emergencies however, for treatment of acute pain do not allow opportunity for 
preventive treatment or hygiene. Risk factors leading to emergency department or other emergency visits require further investigation. A second limitation is that possible explanations for utilization differences in dental care such as attitudes to care are not captured by the BRFSS survey. Another limitation is that BRFSS data is self-recall data and hence subject to recall bias and also social desirability bias, that is if a respondent believes that one should see a dentist annually they might report a dental visit even if one does not occur. Furthermore, the variable used in the analysis for access to dentists---active dentists per 100,000 state population---does not take into account factors such as number of dentists within a state who do not accept Medicaid or the geographic distribution of dentists in a state. Finally, the race/ethnicity variable does not have a distinct American Indian/Alaska Native category. This population designation is merged into the non-Hispanic Other race/ethnicity category.

\section{Conclusions}

HSDs are an independent risk factor strongly associated with lower rates of dental care utilization. Any strategy to enhance the integration of medicine and dentistry should take HSDs into account. In addition, despite national goals for achieving health equity, persistent disparities in dental utilization remain for several demographic groups. Future research about, enhancing interdisciplinary collaboration and strategies targeting interventions for at risk individuals offers the promise of improved oral health.

\section{Abbreviations \\ ACA: Affordable Care Act; BRFSS: Behavioral Risk Factor Surveillance System survey; CDC: Centers for Disease Control and Prevention; FQHCs: Federally Qualified Health Centers; HCP: healthcare provider; HP2020: Healthy People 2020; HSDs: Health service deficits; MSA: metropolitan statistical area; SPSS: Statistical Package for Social Scientists; US: United States; WHO: World Health Organization}

\section{Acknowledgements}

We acknowledge the very helpful comments provided by the peer reviewers of this manuscript.

\section{Funding}

Not applicable.

\section{Availability of data and materials}

Two thousand sixteen BRFSS data and documentation are available from CDC at: https://www.cdc.gov/brfss/annual_data/annual_2016.html

\section{Authors' contributions}

All of the authors contributed equally to this study. MNL, AJG, BS, and MSL worked collaboratively to conceive of the study. MNL performed the data analyses and data management. MNL wrote the first draft of the manuscript. AJG, BS and MSL worked on re-drafting the manuscript and editing the manuscript. All authors read and approved the final manuscript.

\section{Ethics approval and consent to participate}

The Institutional Review Boards (IRBs) of the researchers' institutions recognize that the analysis of de-identified, publicly available data does not constitute human subjects research as defined in federal regulations, and as such does not require IRB review.

\section{Consent for publication}

Not applicable.

\section{Competing interests}

Martin S. Lipsky is an associate editor for the journal BMC Public Health, although was not involved in the review of this manuscript. Otherwise, the authors have no conflicts of interest to report.

\section{Publisher's Note}

Springer Nature remains neutral with regard to jurisdictional claims in published maps and institutional affiliations.

Received: 20 December 2018 Accepted: 25 February 2019

Published online: 05 March 2019

References

1. Martin SA, Simon L. Oral health and medicine integration: overcoming historical artifact to relieve suffering. Am J Public Health. 2017;107:S30-1.

2. Atchison KA, Weintraub JA. Integrating Oral health and primary Care in the Changing Health Care Landscape. N C Med J. 2017;78:406-9.

3. Atchison KA, Weintraub JA, Rozier RG. Bridging the dental-medical divide: Case studies integrating oral health care and primary health care. J Am Dent Assoc. 2018;149:850-8.

4. Myers-Wright N, Lamster IB. A new practice approach for Oral health professionals. J Evid Based Dent Pract. 2016;16:S43-51.

5. US Department of Health and Human Services. Oral health in America: a report of the surgeon general-executive summary. Rockville: US Department of Health and Human Services, National Institute of Dental and Craniofacial Research, National Institutes of Health; 2000.

6. Elter JR, Offenbacher S, Toole JF, Beck JD. Relationship of periodontal disease and edentulism to stroke/TIA. J Dent Res. 2003:82:998-1001.

7. Hung H-C, Joshipura KJ, Colditz G, Manson JE, Rimm EB, Speizer FE, et al. The association between tooth loss and coronary heart disease in men and women. J Public Health Dent. 2007;64:209-15.

8. Willershausen B, Kasaj A, Willershausen I, Zahorka D, Briseño B, Blettner M, et al. Association between chronic dental infection and acute myocardial infarction. J Endod. 2009:35:626-30.

9. Gift HC, Reisine ST, Larach DC. The social impact of dental problems and visits. Am J Public Health. 1992;82:1663-8.

10. Quine S, Morrell S. Hopelessness, depression and oral health concerns reported by community dwelling older Australians. Community Dent Healt. 2009:26:177-82

11. Locker D. Concepts of oral health, disease and the quality of life. In Measuring oral health and quality of life. Chapel Hill: University of North Carolina. Edited by Slade GD. Ecology. Dental; 1997:11-23.

12. Rodrigues SM, Oliveira AC, Vargas AMD, Moreira AN, Ferreira. Implications of edentulism on quality of life among elderly. Int J Environ Res Public Health. 2012;9:100-9.

13. Hugo FN, Hilgert JB, de Sousa ML, Cury JA. Oral status and its association with general quality of life in older independent-living south-Brazilians. Community Dent Oral Epidemiol. 2009;37:231-40.

14. Locker D, Matear D, Stephens M, Jokovic A. Oral health-related quality of life of a population of medically compromised elderly people. Community Dent Health. 2002;19:90-7.

15. Sheiham A. Oral health, general health and quality of life. Bull World Health Organ. 2005;83(9):644.

16. Corbella S, Taschieri S, Francetti L, De Siena F, Del Fabbro M. Periodontal disease as a risk factor for adverse pregnancy outcomes: a systematic review and meta-analysis of case-control studies. Odontology. 2012;100: 232-40.

17. Saman D, Lemieux A, Arevalo O, Lutfiyya MN. A population-based study of edentulism in the US: does depression and rural residency matter after controlling for potential confounders? BMC Public Health. 2014;14:65.

18. Casanova L, Hughes FJ, Preshaw PM. Diabetes and periodontal disease: a two-way relationship. Br Dent J. 2014;217:433-7.

19. Gomes-Filho IS, Soledade-Marques KR, Seixas da Cruz S, de Santana PassosSoares J, Trindade SC, Souza-Machado A, et al. Does periodontal infection have an effect on severe asthma in adults? J Periodontol. 2014:85:e179-87.

20. Scannapieco FA. Individuals with chronic obstructive pulmonary disease (COPD) may be more likely to have more severe periodontal disease than individuals without COPD. J Evid Based Dent Pract. 2014;14:79-81. 
21. World Health Organization. Framework for action in Interprofessional education and collaborative practice. Geneva: World Health Organization; 2010. Available from: http://apps.who.int/iris/bitstream/10665/70185/1/ WHO_HRH_HPN_10.3_eng.pdf?ua=1. Accessed 1 Oct 2018.

22. Healthy People 2020. Washington, DC: U.S. Department of Health and Human Services, Office of Disease Prevention and Health Promotion. Available from: https:/www.healthypeople.gov/2020/about-healthy-people/how-to-usehealthypeople.gov/frequently-asked-questions\#cite. Accessed 3 Aug 2018.

23. Locker D, Maggirias J, Quiñonez C. Income, dental insurance coverage, and financial barriers to dental care among Canadian adults. J Public Health Dent. 2011;71:327-34.

24. Imai S, Mansfield CJ. Oral health in North Carolina: relationship with general health and behavioral risk factors. N C Med J. 2015;76:142-7.

25. Griffin SO, Barker LK, Wei L, Li CH, Albuquerque MS, Gooch BF. Use of Dental Care and Effective Preventive Services in Preventing Tooth Decay Among U.S. Children and Adolescents - Medical Expenditure Panel Survey, United States, 2003-2009 and National Health and Nutrition Examination Survey, United States, 2005-2010. MMWR. 2014;63:54-60.

26. National Quality Forum. Oral health performance measurement: environmental scan, gap analysis and measure topics prioritization-technical report. Washington, DC: National Quality Forum; 2012.

27. Vujicic M, Nasseh K. A decade in dental care utilization among adults and children (2001-2010). Health Serv Res. 2014;49:460-80.

28. Manski RJ, Magder LS. Demographic and socioeconomic predictors of dental care utilization. J Am Dent Assoc. 1998;129:195-200.

29. Manski RJ, Moeller JF, Maas WR. Dental services: an analysis of utilization over 20 years. J Am Dent Assoc. 2001;132:655-64.

30. Manski RJ, Moeller JF, Chen H, Schimmel J, St Clair PA, Pepper JV. Dental usage under changing economic conditions. J Public Health Dent. 2014;74:1-12.

31. Aderonke Akinkugbe A, Lucas-Perry E. Trends in dental visits among the US noninstitutionalized civilian population: findings from BRFSS 1995 - 2008. J Theory Pract Dent Public Health. 2014;1:32-6.

32. Nasseh K, Vujicic M. The impact of Medicaid reform on Children's dental care utilization in Connecticut, Maryland, and Texas. Health Serv Res. 2015; 50:1236-49.

33. Vargas CM, Crall JJ, Schneider DA. Sociodemographic distribution of pediatric dental caries: NHANES III, 1988-1994. J Am Dent Assoc. 1998;129:1229-38.

34. Kim J, Kaste LM. Associations of the type of childcare with reported preventive medical and dental care utilization for 1- to 5-year-old children in the United States. Community Dent Oral Epidemiol. 2013:41:432-40.

35. Montini T, Tseng TY, Patel H, Shelley D. Barriers to dental services for older adults. Am J Health Behav. 2014;38:781-8.

36. Douglass CW, Jiménez MC. Our current geriatric population: demographic and oral health care utilization. Dent Clin North Am. 2014;58:717-28.

37. Manski RJ, Schimmel J, Chen H, Moeller JF. Differences among older adults in the types of dental services used in the United States. Inquiry. 2016;53:1-11.

38. Lee JY. Access to dental health care for children in North Carolina. N C Med J. 2012;73:115-6.

39. Wides C, Alam SR, Mertz E. Shaking up the dental safety-net: elimination of optional adult dental Medicaid benefits in California. J Health Care Poor Underserved 2014;25:S151-S164.

40. Carrion IV, Castañeda H, Martinez-Tyson D, Kline N. Barriers impeding access to primary oral health care among farmworker families in Central Florida. Soc Work Health Care. 2011;50:828-44.

41. H.R. $3590-111^{\text {th }}$ Congress: Patient Protection and Affordable Care Act. www.GovTrack.us. 2009. Available: https://www.govtrack.us/congress/bills/ 111/hr3590. Accessed 4 Aug 2018.

42. St Hill CA, Swanoski MT, Lipsky MS, Lutfiyya MN. A population-based, crosssectional study examining health services deficits of US veterans using 2014 behavioral risk factor surveillance system data: is rural residency an independent risk factor after controlling for multiple covariates? Healthcare (Basel). 2017;5(3)

43. Huot K, Lutfiyya MN, Akers MF, Amaro ML, Swanoski MT, Schweiss SKA. Population-based cross-sectional study of health service deficits for U.S. adults with depression: are there differences between rural and non-rural adults with depression? BMC Health Ser Res. 2013;13:160.

44. Lutfiyya MN, McCullough JE, Saman DM, Lemieux A, Hendrickson SJ, McGrath CA, et al. Rural/urban differences in health services deficits among U.S. adults with arthritis: a population-based study. J Nurs Educ Pract. 2013;3:43-53.

45. Lutfiyya MN, McCullough JE, Lipsky MS. A population-based study of health services deficits for U.S. adults with asthma. J Asthma. 2011;48:931-44.
46. Institute of Medicine, Committee on Monitoring Access to Personal Health Care Services. In: Millman M, editor. Access to Health Care in America. Washington, DC: National Academies Press; 1993.

47. National Healthcare Quality Report, 2013 [Internet]. Chapter 10: Access to Healthcare. Rockville: Agency for Healthcare Research and Quality; 2014. Available from: http://www.ahrq.gov/research/findings/nhgrdr/nhqdr15/access.html.

48. Andersen R. National health surveys and the behavioral model of health services use. Med Care. 2008;46:647-53.

49. Lee JY, Divaris K. The ethical imperative of addressing oral health disparities a unifying framework. J Dent Res. 2014;93:224-30.

50. Phelan JC, Link BG, Tehranifar P. Social conditions as fundamental causes of health inequalities: theory, evidence, and policy implications. J Health Soc Behav. 2010;51:S28-40.

51. Link BG, Phelan JC. Editorial: understanding sociodemographic differences in health—the role of fundamental social causes. Am J Public Health. 1996:86:471-2

52. Iachan R, Pierannunzi C, Healey K, Greenlund KJ, Town M. National weighting of data from the behavioral risk factor surveillance system (BRFSS). BMC Med Res Methodol. 2016;16:155.

53. Chua KP, Sommers BD. Changes in health and medical spending among young adults under health reform. JAMA. 2014;311(23):2437-9.

54. HRSA. Defining Rural Population. Available from: https://search.yahoo.com/ search?p=defining+rural+population\&fr=opensearch. Accessed 22 Jan 2019.

55. American Dental Association. Supply and profile of dentists. Available from: https://www.ada.org/en/science-research/health-policy-institute/data-center/ supply-and-profile-of-dentists. Accessed 5 Aug 2018.

56. Lin M, Li CH, Wei L, Naavaal S, Kolavic GS, Manz MC, et al. Prevalence of past-year dental visit among US adults, 1999-2010: comparison of trends and estimates between the behavioral risk factor surveillance system and three national surveys. J Public Health Dent. 2017;77:105-14.

57. Miloro MB, Vujicic M. Physicians dissatisfied with current referral process to dentists. Health Policy Institute Research Brief. American Dental Association. 2016. Available from: http://www.ada.org/ /media/ADA/

Science\%20and\%20Research/HPI/Files/HPIBrief_0316_5.pdf.

58. Mertz EA. The dental-medical divide. Health Aff. 2016;35:2168-75.

59. Patrick DL, Lee RSY, Nucci M, Grembowski D, Jolles CZ, Milgrom P. Reducing oral health disparities: a focus on social and cultural determinants. BMC Oral Health. 2006;6(Suppl 1):S4.

60. Manski R, Meyehoefer C. Projecting the demand for dental care in 2040. J Dent Educ. 2017:81:e133-45.

61. Davis MM, Hilton TJ, Benson S, Schott J, Howard A, McGinnis P, et al. Unmet dental needs in rural primary care: a clinic, community, and practice-based research network (ORPRN/PROH) collaborative. J Am Board Fam Med. 2010; 23:514-22.

62. Manski RJ, Cooper PF. Characteristics of employers offering dental coverage in the United States. J Am Dent Assoc. 2010;141:700-11.

63. Fisher-Owens SA, Barker JC, Adams S, Chung LH, Gansky SA, Hyde S, et al. Giving policy some teeth: routes to reducing disparities in oral health. Health Aff (Millwood). 2008:27:404-12.

64. Nasseh K, Vujicic M. The impact of the affordable care act's Medicaid expansion on dental care use through 2016. J Public Health Dent. 2017;77:290-4.

65. Goldman AL, Sommers BD. Medicaid expansion gains momentum: postelection prospects and potential implications. JAMA. 2019;321:241-2.

66. Allison RA, Manski RJ. The supply of dentists and access to care in rural Kansas. J Rural Health. 2007;23:198-206.

67. Vargas CM, Dye BA, Hayes K. Oral health care utilization by US rural residents, National Health Interview Survey 1999. J Public Health Dent. 2003;63:150-7.

68. Geiger CK, Kranz AM, Dick AW, Duffy E, Sorbero M, Stein BD. Delivery of preventive oral health services by rurality: a cross-sectional analysis. J Rural Health. 2018. https://doi.org/10.1111/jrh.12340. Epub ahead of print.

69. Khan A, Thapa JR, Zhang D. Preventive dental checkups and their association with access to usual source of care among rural and urban adult residents. J Rural Health. 2017:33:419-26.

70. Meyer MS, Joshipura K, Giovannucci E, Michaud DS. A review of relationship between tooth loss, periodontal disease and Cancer. Cancer Causes Control. 2008:19:895-907.

71. Sciubba JJ. Oral cancer. The importance of early diagnosis and treatment. Am J Clin Dermatol. 2001;2:239-51. 